\title{
Performance differences between sexes in 50-mile to 3,100-mile ultramarathons
}

This article was published in the following Dove Press journal:

Open Access Journal of Sports Medicine

22 January 2015

Number of times this article has been viewed

\section{Matthias A Zingg' \\ Beat Knechtle ${ }^{1,2}$ \\ Thomas Rosemann' \\ Christoph A Rüst'}

'Institute of Primary Care, University of Zurich, Zurich, Switzerland;

${ }^{2}$ Gesundheitszentrum St Gallen,

St Gallen, Switzerland
Correspondence: Beat Knechtle Facharzt FMH für Allgemeinmedizin, Gesundheitszentrum St Gallen, Vadianstrasse 26, 900I St Gallen, Switzerland

Tel +4l 7l 2268282

Fax +4I 7| 2268272

Email beat.knechtle@hispeed.ch
Abstract: Anecdotal reports have assumed that women would be able to outrun men in longdistance running. The aim of this study was to test this assumption by investigating the changes in performance difference between sexes in the best ultramarathoners in 50-mile, 100-mile, 200-mile, 1,000-mile, and 3,100-mile events held worldwide between 1971 and 2012. The sex differences in running speed for the fastest runners ever were analyzed using one-way analysis of variance with subsequent Tukey-Kramer posthoc analysis. Changes in sex difference in running speed of the annual fastest were analyzed using linear and nonlinear regression analyses, correlation analyses, and mixed-effects regression analyses. The fastest men ever were faster than the fastest women ever in 50-mile (17.5\%), 100-mile (17.4\%), 200-mile (9.7\%), 1,000mile $(20.2 \%)$, and 3,100-mile (18.6\%) events. For the ten fastest finishers ever, men were faster than women in 50-mile (17.1\% $\pm 1.9 \%)$, 100-mile (19.2\% $1.5 \%)$, and 1,000-mile $(16.7 \% \pm 1.6 \%)$ events. No correlation existed between sex difference and running speed for the fastest ever $\left(r^{2}=0.0039, P=0.91\right)$ and the ten fastest ever $\left(r^{2}=0.15, P=0.74\right)$ for all distances. For the annual fastest, the sex difference in running speed decreased linearly in 50-mile events from $14.6 \%$ to $8.9 \%$, remained unchanged in 100 -mile $(18.0 \% \pm 8.4 \%)$ and 1,000 -mile $(13.7 \% \pm 9.1 \%)$ events, and increased in 3,100-mile events from $12.5 \%$ to $16.9 \%$. For the annual ten fastest runners, the performance difference between sexes decreased linearly in 50 -mile events from $31.6 \% \pm 3.6 \%$ to $8.9 \% \pm 1.8 \%$ and in 100 -mile events from $26.0 \% \pm 4.4 \%$ to $24.7 \% \pm 0.9 \%$. To summarize, the fastest men were $\sim 17 \%-20 \%$ faster than the fastest women for all distances from 50 miles to 3,100 miles. The linear decrease in sex difference for 50-mile and 100-mile events may suggest that women are reducing the sex gap for these distances.

Keywords: running, sex difference, running speed, ultraendurance

\section{Introduction}

In an evolving world where performance differences between sexes in daily life (eg, education and work) are fading in first world countries, women are challenging men more and more in sports activities. The discussion about whether women will eventually outpace men in running or ultrarunning has been going on for decades and is still ongoing..$^{1-5}$ In the last few years, more cases of women outperforming men have been made public. ${ }^{6-8}$ For example, Ann Trason won the 1989 US 24-Hour Championship in Flushing Meadow Park and was the first woman ever to win a National Championship in the United States. ${ }^{6}$ In 2002 and 2003, Pamela Reed won the Badwater ultramarathon by surpassing all men. ${ }^{7}$ In 2007, the female Japanese ultramarathoner Hiroko Okiyama won the 1,200 km multistage Deutschlandlauf ultramarathon. ${ }^{8}$ These successes have triggered speculation about whether the results were insignificant exceptions or 
represented a trend toward more-competitive women. Beneke et $\mathrm{al}^{3}$ provided an explanation for the hypotheses of women's future dominance in ultraendurance performance, suggesting that the length of a race might confer an advantage for women and that it should only be a question of time to find a distance where women would dominate men. ${ }^{3}$

The discussion about performance differences between sexes in sports is not focused on running only. Recently, Ye Shiwen's world record time in $400 \mathrm{~m}$ medley swimming at the 2012 Olympic Games in London surprised the sports community. The 16-year-old Chinese athlete swam the last $100 \mathrm{~m} 0.17$ seconds faster than Michael Phelps had done just minutes before. ${ }^{9}$ Anecdotal reports like this nurture the discussion about whether women will be able to outperform men.

Different research teams investigated whether women would be able to outperform men at certain distances in running and other sports. For example, Thibault et al ${ }^{10}$ reported a constant performance difference between sexes of $\sim 10.7 \%$ for running distances ranging from $100 \mathrm{~m}$ to the classical marathon distance. Cheuvront et $\mathrm{al}^{4}$ found a stable performance difference between sexes of $\sim 8 \%-14 \%$ in running races from $1,500 \mathrm{~m}$ to the marathon. In longer running distances, Coast et $\mathrm{al}^{11}$ reported for distances from $100 \mathrm{~m}$ to $200 \mathrm{~km}$ a mean performance difference between sexes of $\sim 12.4 \%$, whereas the sex difference in performance seemed to grow with increasing race distance. Therefore, Beneke's assumption of a decrease in performance difference between sexes with increasing race distance would be disproved. ${ }^{3}$

Another approach of researchers was to extrapolate retrospective data for prospective predictions about women's performance. During the 1990s, Whipp and Ward ${ }^{1}$ expected the intersection of running performance of the two sexes in marathon running to happen around the millennium change, which has, however, not occurred. ${ }^{12,13}$ They furthermore projected that the performance difference between sexes in races from $200 \mathrm{~m}$ to the marathon could disappear by $2050 .{ }^{1}$ They based their assumption on the findings that the world record progression in the various events (ie, $200 \mathrm{~m}$, $400 \mathrm{~m}, 800 \mathrm{~m}, 1,500 \mathrm{~m}, 5,000 \mathrm{~m}, 10,000 \mathrm{~m}$, and marathon) was linear over an interval of approximately a century. ${ }^{1}$ In another study published in Nature, Tatem et $\mathrm{al}^{5}$ extrapolated the 100 m Olympic running sprints results from 1904 to 2004 and projected that women will overtake men in the 2156 Olympic Games. However, not only conventional athletics running distances were discussed. Bam et $\mathrm{al}^{2}$ questioned whether women could outrun men in ultramarathon races above $66 \mathrm{~km}$ in length.
Therefore, supporting these different theories, it should only be a question of time to find a running distance where women would close the sex gap and dominate men. Different ultrarunning studies provided support for Beneke's assumptions. ${ }^{3,14-16}$ A new approach in this field was to compare the same runners over two different distances and to evaluate the performance difference between sexes thereafter. Speechly et $\mathrm{al}^{17}$ compared performances of both sexes in a $90 \mathrm{~km}$ event while assessing marathon times of female and male runners. They found that women performed better than men after $90 \mathrm{~km}$. Hoffman ${ }^{18}$ did not confirm this finding in a study matching both sexes in performance in a $50 \mathrm{~km}$ race and then investigating their performance in $80 \mathrm{~km}$ and $161 \mathrm{~km}$ races. At least, women and men performed similarly in ultramarathons of $80 \mathrm{~km}$ and $161 \mathrm{~km}$ distances. ${ }^{18}$

Another concern about the sex difference in performance was the sample size in the studies. Because a considerably higher percentage of men finish ultramarathons than women, ${ }^{14,19,20}$ the density of elite runners is lower in women than in men. Therefore, larger cohorts are needed to find significant results. For example, Deaner and Mitchell ${ }^{21}$ investigated the fastest running times in 342 US road races ranging from $5 \mathrm{~km}$ to the marathon distance. They found that around four times more men than women were running "relatively fast," which they defined as finishing a race within $110 \%$ of the corresponding sex-specific world record. For example, the 2012 Olympic " $\mathrm{A}$ " qualifying standard for the marathon was 2 hours 15 minutes for men (9.2\% over the current men's world record) and 2 hours 37 minutes for women (15.9\% over the current women's world record).

The controversial discussion will be going on whenever a woman tops men's results. In running, this was expected most likely to happen in ultraendurance events, ${ }^{3}$ but it was never systematically analyzed in races over a series of different ultradistances. ${ }^{11}$ Although women have been able to beat men in some instances of running or ultrarunning, ${ }^{6-7}$ a performance difference between sexes of $\sim 11 \%-12 \%$ in endurance and ultraendurance performance will remain, ${ }^{10,11}$ most probably due to differences in aerobic capacity and muscular strength between women and men. ${ }^{4}$

A study including ultramarathon distances up to the longest road-race distances (such as 3,100 miles) is required to evaluate whether women will outrun men sometime. In this context, the first aim of the current study was to investigate the best runners competing from 1971 to 2012 in 50-mile to 3,100-mile ultramarathons for change in running performance differences between sexes and to evaluate whether women will outperform men in the next few years by using 
linear and nonlinear regression analyses. The second aim was to determine the performance difference between sexes in ultramarathon running for the fastest finishers ever.

\section{Materials and methods Ethics}

All procedures used in the study met the ethical standards of the Swiss Academy of Medical Sciences and were approved by the Institutional Review Board of Kanton St Gallen, Switzerland, with a waiver of the requirement for informed consent of the participants given the fact that the study involved the analysis of publicly available data.

\section{Data sampling}

All athletes who ever participated between 1971 and 2012 in a 50-mile, 100-mile, 200-mile, 1,000-mile, or 3,100-mile ultramarathon were analyzed for participation, running speed, age, and sex. The data set for this study was obtained from the race website http://www.ultra-marathon.org of the Deutsche Ultramarathon Vereinigung (DUV). ${ }^{22}$ The DUV was founded in 1985 and has become the largest ultramarathon association worldwide. Overall, 1,600 members collected race results of ultramarathons held worldwide to build the most substantial dataset of ultramarathon statistics in the world. However, we are aware of the possibility that not all race results of the mentioned distances may be listed by the DUV. Table 1 presents the year when the first race for a specific distance was held, the number of events held in the first year of the event, and the number of races held in 2012.

\section{Data analysis}

In total, 128,719 ultrarunners (26,837 women and 101,882 men) were included for data analysis (Table 2). To determine the change in sex difference in peak running performance across years, race times of the annual fastest and of the annual ten fastest women and men were extracted from the race results. Race distances given in miles were converted to kilometers. To enable the comparability between different

Table I Number of events held during the period I97|-2012

\begin{tabular}{llll}
\hline Distance & $\begin{array}{l}\text { Year when } \\
\text { the first event } \\
\text { was held }\end{array}$ & $\begin{array}{l}\text { Number of events } \\
\text { held in the first } \\
\text { year }\end{array}$ & $\begin{array}{l}\text { Number } \\
\text { of events } \\
\text { held in 20 I 2 }\end{array}$ \\
\hline 50 miles & 1971 & 2 & 52 \\
100 miles & 1974 & $\mathrm{I}$ & $\mathrm{III}$ \\
200 miles & 2012 & $\mathrm{I}$ & 3 \\
1,000 miles & 1984 & $\mathrm{I}$ & $\mathrm{I}$ \\
3,100 miles & 2003 & $\mathrm{I}$ & $\mathrm{I}$ \\
Overall & & 6 & 168 \\
\hline
\end{tabular}

Table 2 Total number of female, male, and overall finishers up to and including 20I2, by sex and distance

\begin{tabular}{llll}
\hline $\begin{array}{l}\text { Finishers per } \\
\text { distance }\end{array}$ & Women & Men & Overall \\
\hline 50 miles & $18,688(22.3 \%)$ & $65,216(77.7 \%)$ & 83,904 \\
100 miles & $8,108(18.2 \%)$ & $36,519(81.8 \%)$ & 44,627 \\
200 miles & $3(12.0 \%)$ & $22(88.0 \%)$ & 25 \\
1,000 miles & $31(33.3 \%)$ & $62(66.7 \%)$ & 93 \\
3,100 miles & $7(10.0 \%)$ & $63(90.0 \%)$ & 70 \\
Overall & $26,837(20.8 \%)$ & $101,882(79.2 \%)$ & 128,719 \\
\hline
\end{tabular}

distances given in miles, all race times were converted to running speed ( $\mathrm{km} /$ hour) using the equation [speed ( $\mathrm{km} /$ hour)] $=[$ distance $(\mathrm{km})] /[$ time (hours) $]$. The sex difference in running speed was calculated using the equation ([running speed in women] - [running speed in men])/[running speed in men] $\times 100$, where the performance difference between sexes was calculated for every pair of equally placed athletes (eg, between male and female winner, between male and female second place, etc) before calculating mean values and standard deviations for all the pairs. When fewer than the required number of athletes (ie, annual ten fastest) were available in a specific year for a certain distance, the respective year and distance was excluded for statistical analysis. To find the absolute peak running speed of the fastest runners ever in these races, running speed of the overall top and the overall top ten women and men ever were determined. The performance difference between sexes in absolute peak running speed was determined by comparing the absolute peak running speed of both sexes. The performance difference between sexes for the top and the top ten ever women and men were determined and compared as described above. To find a relationship between performance difference between sexes and running speed, the performance differences between sexes were compared between the top and the top ten women and men ever.

\section{Statistical analysis}

Each set of data was tested for normal distribution and for homogeneity of variances prior to statistical analyses. Normal distribution was tested using a D'Agostino and Pearson omnibus normality test, and homogeneity of variances was tested using a Levene's test. Trends in participation were analyzed using regression analysis with a "straight line" and "exponential growth equation" model, whereas for each set of data (eg, each sex), both models were compared using Akaike's Information Criteria (AIC) to decide which model showed the highest probability of correctness. To determine changes in performance and performance differences between sexes of 
the annual top and the annual top ten women and men, we used a mixed-effects regression model with finisher as a random variable to consider finishers who completed several races. We included sex, distance, centered age, squared centered age, and calendar year as fixed variables. We also considered interaction effects between sex or distance and centered age, between sex or distance and squared centered age, and between sex and distance, and the final model was selected by means of AIC. Since the change in performance difference between sexes in endurance is assumed to be nonlinear, ${ }^{23}$ we calculated both the linear and nonlinear regression models for running speed and performance difference between sexes. In order to find the best model to explain the trend of the data, we compared the best-fit nonlinear models to the linear model using AIC and $F$-tests. To compare running speed and performance differences between sexes between multiple groups (eg, men versus women or between different distances), a one-way analysis of variance with subsequent Tukey-Kramer posthoc analysis (ie, one family per row in case of two-dimensional array of data) was used. A potential relationship between the performance difference between sexes of the fastest runners and running speed was investigated using correlation analysis. Statistical analyses were performed using IBM SPSS Statistics (Version 22; IBM Corporation, Armonk, NY, USA) and GraphPad Prism (Version 6.01; GraphPad Software, Inc., La Jolla, CA, USA). Significance was accepted at $P<0.05$ (two-sided for Student's $t$-tests). Data in the text and figures are given as mean \pm standard deviation.

\section{Results}

\section{Number of races, finishers and number of finishers per race}

The two most commonly held ultramarathon distances were 50 miles and 100 miles (Table 1). The number of events held in 50-mile $\left(\mathrm{y}=0.16 \times^{(0.17 \times x)}\right), 100$-mile $\left(y=0.35 \times^{(0.14 \times x)}\right), 200$-mile $\left(\mathrm{y}=4.98 \times 10^{-16} \times^{(0.55 \times \mathrm{x})}\right), 1,000$-mile $(\mathrm{y}=0.03 \times \mathrm{x}+0.12)$ and 3,100 -mile $\left(y=0.01 \times^{(0.13 \times x)}\right)$ events increased exponentially. In total, 128,719 ultrarunners, with 26,837 women $(20.8 \%)$ and 101,882 men (79.2\%), finished a race in 50-mile, 100mile, 200-mile, 1,000-mile or 3,100-mile events (Table 2). The number of finishers increased for both sexes in both 50-mile and 100-mile events. In 50-mile races, the increase in female $\left(\mathrm{y}=0.53 \times^{(0.21 \times x)}\right)$ and male $\left(\mathrm{y}=5.93 \times^{(0.18 \times \mathrm{x})}\right)$ finishers was exponential. An exponential increase in female $(y=$ $\left.2.46 x^{(0.15 \times x)}\right)$ and male $\left(y=22.8 x^{(0.12 \times x)}\right)$ finishers was found in 100 -mile events as well. The number of finishers in 200-mile, 1,000-mile, and 3,100-mile was low, with a total of 25, 93, and 70 overall finishers, respectively (Table 2). The number of finishers per race decreased for both sexes with increasing race distance from 50 miles to 100 miles (Table 3). The number of finishers per race was lower in the longer race distances and was generally very low for 200-mile, 1,000-mile, and 3,100mile events (Table 3 ). The men-to-women ratio in the number of finishers is presented in Table 4. In the first years of these races, only men started. In 50-mile races, the first man finished an event as early as 1971, while the first woman finished a 50-mile race in 1977. Female participation was low at first; however, the men-to-women ratio decreased across years. The mean value for the men-to-women ratio was highest in 50-mile races and lowest in 3,100-mile races (Table 4).

\section{Change in running speed across years of the annual fastest runners}

Figure 1 presents the change in running speed for the annual fastest women and men in 50-mile to 3,100-mile events. In 50-mile races, running speed increased linearly and significantly from $12.2 \mathrm{~km} /$ hour (1977) to $14.3 \mathrm{~km} /$ hour (2012) for the annual fastest women but showed no change for men, with a mean running speed of $14.4 \pm 1.0 \mathrm{~km} /$ hour (Table 5). In 100-mile events, the annual fastest women increased peak running speed significantly and nonlinearly (ie, polynomial regression seventh degree, $r^{2}=0.84$, standard error $=0.47$ ), from $5.44 \mathrm{~km} /$ hour (1978) to $10.71 \mathrm{~km} /$ hour (1978). The annual fastest men increased peak running speed significantly and linearly, from $6.79 \mathrm{~km} /$ hour (1971) to $13.82 \mathrm{~km} /$ hour (2012) (Table 5). In 1,000-mile events, men's peak running speed decreased significantly and linearly from $5.65 \mathrm{~km} /$ hour (1974) to $4.19 \mathrm{~km} /$ hour (2012) (Table 5). For 200-mile races, not enough data were available for analysis. In 3,100-mile events, men's peak running speed increased significantly and linearly, from $2.63 \mathrm{~km} /$ hour (2003) to $2.89 \mathrm{~km} /$ hour (2011). For women, peak running speed increased significantly and linearly, from $2.30 \mathrm{~km} /$ hour (2003) to $2.40 \mathrm{~km} /$ hour (2011) (Table 5). There was a significant interaction for sex and race distance in the 1,000-mile events.

Table 3 Male and female finishers for each distance from 197I2012

\begin{tabular}{llllll}
\hline Distance (miles) & $\mathbf{5 0}$ & $\mathbf{1 0 0}$ & $\mathbf{2 0 0}$ & $\mathbf{I , 0 0 0}$ & $\mathbf{3 , 1 0 0}$ \\
\hline Number of races & $\mathrm{I}, 129$ & 860 & 5 & 29 & 10 \\
Number of finishers & 83,904 & 44,627 & 25 & 92 & 70 \\
Number of male finishers & 65,216 & 36,519 & 22 & 61 & 63 \\
$\begin{array}{l}\text { Number of female finishers } \\
\text { Number of male finishers }\end{array}$ & 57,688 & 8,108 & 3 & 31 & 7 \\
$\begin{array}{l}\text { per race } \\
\text { Number of female finishers }\end{array}$ & 16.55 & 42.46 & 4.40 & 2.10 & 6.30 \\
per race & & & 0.60 & 1.07 & 0.70 \\
\hline
\end{tabular}


Table 4 The number of women, men, and the men-to-women ratio for each distance across calendar years

\begin{tabular}{|c|c|c|c|c|c|c|c|c|c|c|c|c|c|c|c|}
\hline \multirow[t]{2}{*}{ Year } & \multicolumn{3}{|c|}{50 miles } & \multicolumn{3}{|c|}{100 miles } & \multicolumn{3}{|c|}{200 miles } & \multicolumn{3}{|c|}{1,000 miles } & \multicolumn{3}{|c|}{3,100 miles } \\
\hline & $\mathbf{W}$ & $\mathbf{M}$ & M/W & $\mathbf{W}$ & $\mathbf{M}$ & M/W & $\mathbf{W}$ & $\mathbf{M}$ & M/W & $\mathbf{W}$ & $\mathbf{M}$ & M/W & W & $M$ & M/W \\
\hline 1971 & & 16 & & & & & & & & & & & & & \\
\hline 1972 & & 4 & & & & & & & & & & & & & \\
\hline 1973 & & 28 & & & & & & & & & & & & & \\
\hline 1974 & & 32 & & & 1 & & & & & & & & & & \\
\hline 1975 & & 27 & & & & & & & & & & & & & \\
\hline 1976 & & 34 & & & 1 & & & & & & & & & & \\
\hline 1977 & 4 & 36 & 9 & & 3 & & & & & & & & & & \\
\hline 1978 & & 70 & & 1 & 29 & 29 & & & & & & & & & \\
\hline 1979 & 6 & 64 & 11 & 6 & 112 & 19 & & & & & & & & & \\
\hline 1980 & 2 & 58 & 29 & 15 & 129 & 9 & & & & & & & & & \\
\hline 1981 & 13 & 159 & 12 & 18 & 128 & 7 & & & & & & & & & \\
\hline 1982 & 28 & 379 & 14 & 17 & 159 & 9 & & & & & & & & & \\
\hline 1983 & 25 & 366 & 15 & 35 & 175 & 5 & & & & & & & & & \\
\hline 1984 & 25 & 382 & 15 & 31 & 227 & 7 & & & & & & & & & \\
\hline 1985 & 33 & 408 & 12 & 25 & 161 & 6 & & & & & & & & & \\
\hline 1986 & 48 & 378 & 8 & 34 & 279 & 8 & & & & & 5 & & & & \\
\hline 1987 & 42 & 317 & 8 & 23 & 238 & 10 & & & & & & & & & \\
\hline 1988 & 58 & 372 & 6 & 40 & 345 & 9 & & & & 1 & 5 & 5 & & & \\
\hline 1989 & 61 & 458 & 8 & 62 & 370 & 6 & & & & 3 & 6 & 2 & & & \\
\hline 1990 & 75 & 444 & 6 & 65 & 359 & 6 & & & & & & & & & \\
\hline $199 \mid$ & 67 & 473 & 7 & 62 & 289 & 5 & & & & & & & & & \\
\hline 1992 & 79 & 534 & 7 & 35 & 278 & 8 & & & & & & & & & \\
\hline 1993 & 67 & 482 & 7 & 68 & 351 & 5 & & & & 4 & 4 & I & & & \\
\hline 1994 & 79 & 591 & 7 & 56 & 341 & 6 & & & & 4 & 2 & I & & & \\
\hline 1995 & 143 & 814 & 6 & 66 & 355 & 5 & & & & & 1 & & & & \\
\hline 1996 & 178 & 964 & 5 & 133 & 837 & 6 & & & & 2 & 9 & 5 & & & \\
\hline 1997 & 289 & I,408 & 5 & 145 & 1,040 & 7 & & & & 3 & 3 & I & & & \\
\hline 1998 & 319 & $|, 62|$ & 5 & 242 & I, I80 & 5 & & & & I & 6 & 6 & & & \\
\hline 1999 & 354 & 1,809 & 5 & 220 & I,097 & 5 & & & & I & 1 & I & & & \\
\hline 2000 & 342 & 1,642 & 5 & 241 & 1,247 & 5 & & & & 3 & 2 & I & & & \\
\hline 2001 & 419 & 1,692 & 4 & 284 & 1,245 & 4 & & & & 2 & 2 & 1 & & & \\
\hline 2002 & 478 & I,777 & 4 & 260 & I, I88 & 5 & & & & I & 1 & I & & & \\
\hline 2003 & 581 & I,985 & 3 & 322 & I,398 & 4 & & & & 3 & 1 & & & 4 & \\
\hline 2004 & 523 & 1,859 & 4 & 361 & $\mathrm{I}, 474$ & 4 & & & & & & & & 8 & \\
\hline 2005 & 700 & 2,321 & 3 & 360 & I,557 & 4 & & & & & & & I & 1 & I \\
\hline 2006 & 964 & 3,051 & 3 & 401 & I,776 & 4 & & & & & 6 & & & 14 & \\
\hline 2007 & $\mathrm{I}, 166$ & 3,599 & 3 & 480 & 1,980 & 4 & & & & & & & I & 1 & I \\
\hline 2008 & 1,349 & 4,108 & 3 & 469 & I,99| & 4 & & & & & & & & 11 & \\
\hline 2009 & 1,915 & 5,853 & 3 & 660 & 2,613 & 4 & & & & & & & & 11 & \\
\hline 2010 & 2,452 & 7,537 & 3 & 809 & 3,331 & 4 & & 2 & & 3 & 5 & 2 & & 6 & \\
\hline 2011 & 2,859 & 8,964 & 3 & 926 & 3,760 & 4 & & I & & & & & & 8 & \\
\hline 2012 & 3,524 & 10,275 & 3 & 1,193 & 4,857 & 4 & 3 & 19 & 6 & & 1 & & & 6 & \\
\hline Mean & & & 7 & & & 7 & & & 6 & & & 2 & & & 1 \\
\hline
\end{tabular}

Abbreviations: $M$, men; $M / W$, men-to-women ratio; $W$, women.

\section{Change in running speed across years of the annual ten fastest runners}

Figure 2 presents changes in running speed for the annual ten fastest women and men in 50-mile and 100-mile events. In 50-mile races, peak running speed of the annual ten fastest runners increased significantly and linearly for women, from $9.59 \pm 0.83 \mathrm{~km} /$ hour (1981) to $13.51 \pm 0.63 \mathrm{~km} / \mathrm{hour}$ (2012), but not for men, with a mean running speed of $13.6 \pm 0.8 \mathrm{~km} /$ hour (Table 6). In 100-mile races, running speed increased in the annual ten fastest women significantly and linearly, from $6.51 \pm 0.68 \mathrm{~km} /$ hour (1980) to $9.96 \pm 0.34 \mathrm{~km} /$ hour (2012), whereas running speed increased nonlinearly (ie, polynomial regression, sixth degree, $r^{2}=0.78$, standard error $=0.44$ ) in the annual ten fastest men, from $7.58 \pm 0.52 \mathrm{~km} /$ hour (1978) to $12.71 \pm 0.53 \mathrm{~km} /$ hour (2012) (Table 6). Running speed was unchanged at $4.3 \pm 0.1 \mathrm{~km} /$ hour in the annual ten fastest men in 3,100-mile events, while not enough data were available for women. For 200-mile and 1,000-mile events, not enough 

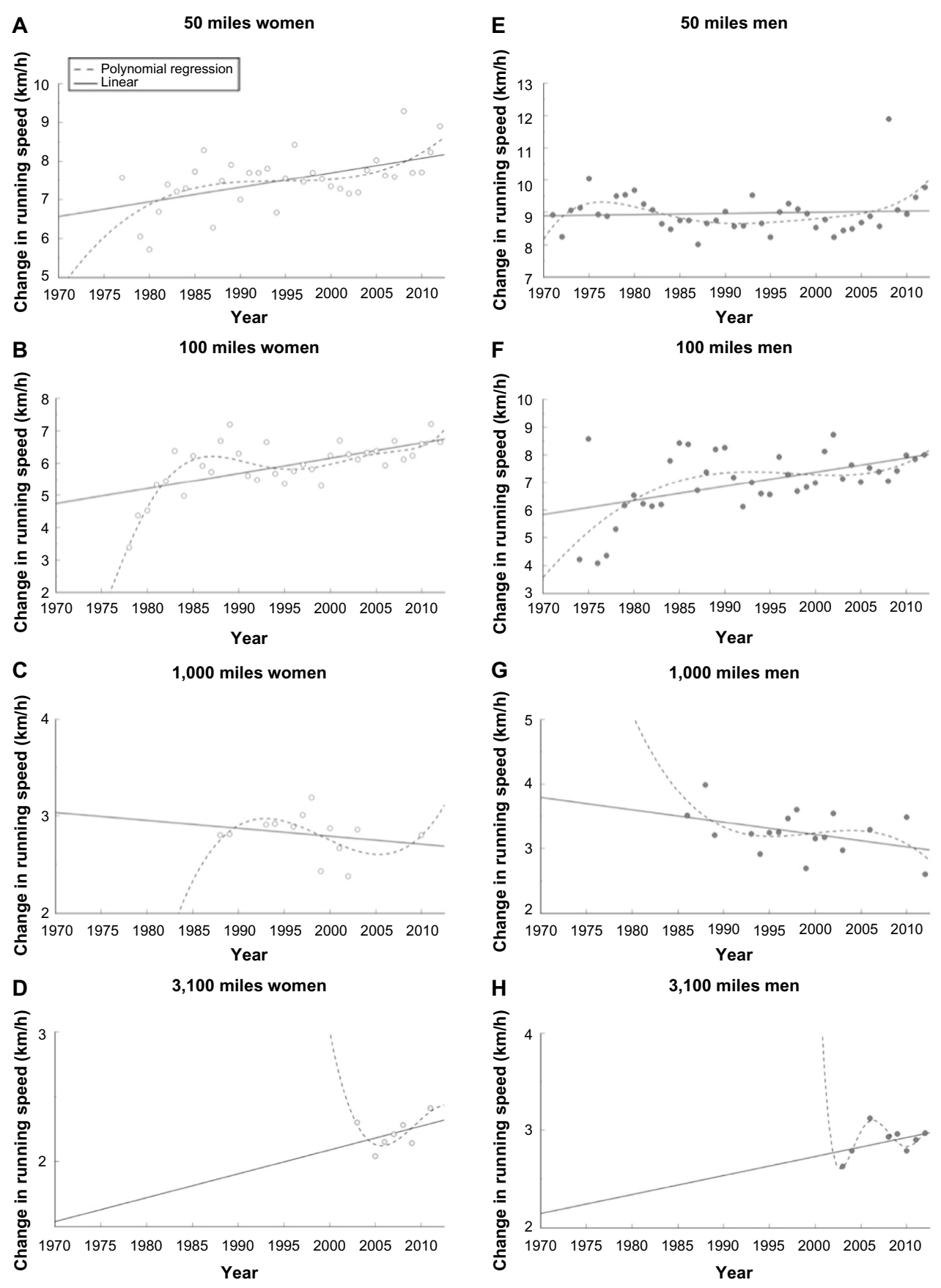

Figure I Running speed across calendar years from 50-mile to 3,100-mile events for the annual fastest runners. Notes: (A-D) Women. (E-H) Men.

data were available. There was a significant interaction for race distance and both sex and age for 100-mile events.

\section{Change in performance difference between sexes in running speed across years in the annual fastest and annual ten fastest}

The performance difference between sexes decreased linearly in the annual fastest runners in 50-mile events, from $14.6 \%$ (1977) to $8.9 \%$ (2012), but remained unchanged in the annual fastest runners in 100 -mile $(18.0 \% \pm 8.4 \%)$ and 1,000-mile (13.7\% $\pm 9.1 \%)$ events. In 3,100-mile events, the performance difference between sexes increased from $12.5 \%$ (2003) to $16.9 \%$ (2011) (Figure 3, Table 7). There was a significant interaction for race distance and age for 3,100mile events (Table 7). For the annual ten fastest runners, the performance difference between sexes decreased linearly in 50 -mile races, from $31.6 \% \pm 3.6 \%$ (1981) to $8.9 \% \pm 1.8 \%$ (2012), and in 100-mile events, from $26.0 \% \pm 4.4 \%$ (1980) to $24.7 \% \pm 0.9 \%$ (2012) (Figure 4, Table 8). 
Table 5 Coefficients and standard errors from multivariate regression models for running speed of the annual fastest runners for each calendar year

\begin{tabular}{|c|c|c|c|}
\hline & C & SE & $P$-value \\
\hline Intercept & -44.47 & 9.77 & $<0.001$ \\
\hline Sex (female) & $-|.5|$ & 0.15 & $<0.001$ \\
\hline Year & 0.026 & 0.0048 & $<0.001$ \\
\hline \multicolumn{4}{|l|}{ Distance } \\
\hline 3,100 miles & -6.38 & 0.35 & $<0.001$ \\
\hline $\mathrm{I}, 000$ miles & -5.55 & 0.25 & $<0.001$ \\
\hline 100 miles & -1.60 & 0.16 & $<0.001$ \\
\hline \multicolumn{4}{|l|}{ Age } \\
\hline Linear & 0.019 & 0.015 & 0.193 \\
\hline Squared & 0.002 & 0.001 & 0.193 \\
\hline \multicolumn{4}{|l|}{ Interaction sex $\times$ distance } \\
\hline Female $\times 3,100$ miles & 0.698 & 0.660 & 0.292 \\
\hline Female $\times I, 000$ miles & 0.993 & 0.311 & 0.002 \\
\hline Female $\times 100$ miles & 0.148 & 0.022 & 0.460 \\
\hline \multicolumn{4}{|c|}{ Interaction distance $\times$ age linear } \\
\hline 3,100 miles $\times$ age & 0.057 & 0.167 & 0.734 \\
\hline I,000 miles $\times$ age & -0.009 & 0.020 & 0.633 \\
\hline 100 miles $\times$ age & 0.006 & 0.017 & 0.702 \\
\hline \multicolumn{4}{|l|}{ Interaction distance $\times$ age $^{2}$} \\
\hline 3,100 miles $\times$ age $^{2}$ & -0.006 & 0.010 & 0.535 \\
\hline I,000 miles $\times$ age $^{2}$ & -0.003 & 0.002 & 0.067 \\
\hline 100 miles $\times$ age $^{2}$ & -0.002 & 0.002 & 0.352 \\
\hline \multicolumn{4}{|l|}{ Interaction se $\times$ age } \\
\hline Female $\times$ age & -0.014 & 0.015 & 0.325 \\
\hline \multicolumn{4}{|l|}{ Interaction sex $\times$ age $^{2}$} \\
\hline Female $\times$ age $^{2}$ & 0.0007 & 0.0012 & 0.560 \\
\hline
\end{tabular}

Abbreviations: $\mathrm{C}$, coefficient; SE, standard error.
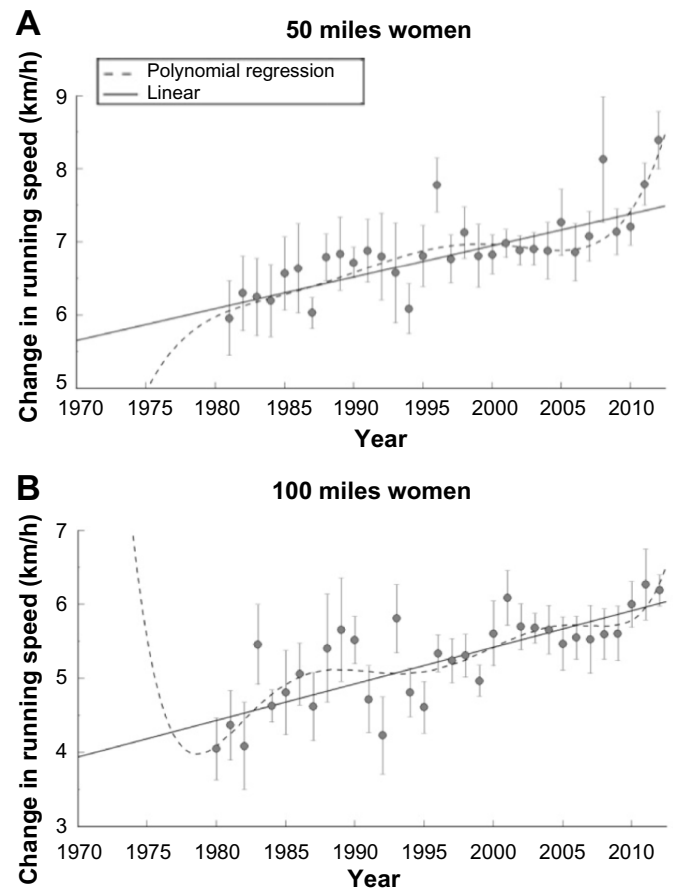

\section{Running speed of the fastest finishers ever}

Figure 5 presents the running speed for all distances from 50 miles to 3,100 miles for the fastest runners ever, the ten fastest runners ever, and all finishers. Men were running faster than women for all distances when the fastest runners ever were considered. For the ten fastest finishers ever, men were faster in 50-mile and 100 -mile events, but not in 1,000-mile races. When all finishers were considered, men were faster in 50-mile and 100-mile races, but not in 200-mile, 1,000-mile, and 3,100-mile events.

\section{Performance differences between sexes for the fastest finishers ever}

Figure 6 summarizes the performance differences between sexes for the fastest finishers ever from 50-mile to 3,100mile events and for the ten fastest finishers ever for 50-mile, 100-mile, and 1,000-mile events. In 200-mile and 3,100-mile events, fewer than 10 women ever finished (Table 2). The fastest men ever were faster than the fastest women ever in 50-mile (17.5\%), 100-mile (17.4\%), 200-mile (9.7\%), 1,000-mile (20.2\%), and 3,100-mile (18.6\%) events. For the ten fastest finishers ever, men were faster than women in 50 -mile $(17.1 \% \pm 1.9 \%), 100$-mile $(19.2 \% \pm 1.5 \%)$, and 1,000 -mile $(16.7 \% \pm 1.6 \%)$ events.
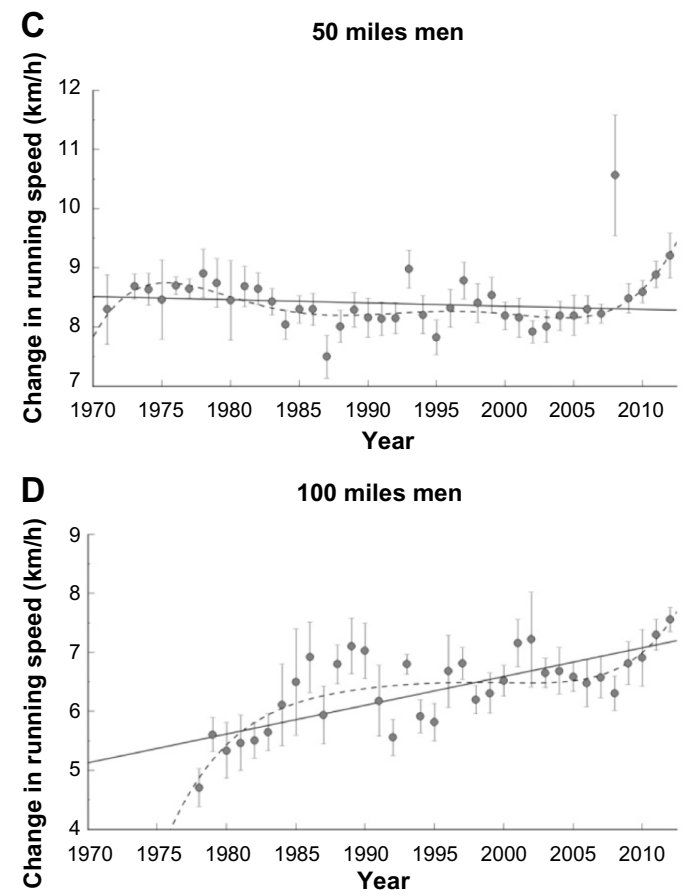

Figure 2 Running speed across calendar years from 50-mile and 100-mile events for the annual ten fastest runners.

Notes: (A and $\mathbf{B})$ Women. $(\mathbf{C}$ and $\mathbf{D})$ Men. 
Table 6 Coefficients and standard errors from multivariate regression models for running speed of the annual ten fastest runners for each calendar year

\begin{tabular}{|c|c|c|c|}
\hline & C & SE & $P$-value \\
\hline Intercept & -62.31 & 4.14 & $<0.0001$ \\
\hline Sex (female) & $-|.5|$ & 0.059 & $<0.0001$ \\
\hline Year & 0.035 & 0.0020 & $<0.0001$ \\
\hline \multicolumn{4}{|l|}{ Distance } \\
\hline 100 miles & -1.82 & 0.051 & $<0.0001$ \\
\hline \multicolumn{4}{|l|}{ Age } \\
\hline Linear & -0.0036 & 0.0048 & 0.451 \\
\hline Squared & -0.00017 & $0.0005 I$ & 0.734 \\
\hline \multicolumn{4}{|c|}{ Interaction sex $\times$ distance } \\
\hline Female $\times 100$ miles & 0.196 & 0.650 & 0.003 \\
\hline \multicolumn{4}{|c|}{ Interaction distance $\times$ age linear } \\
\hline 100 miles $\times$ age & 0.015 & 0.0050 & 0.002 \\
\hline \multicolumn{4}{|c|}{ Interaction distance $\times$ age $^{2}$} \\
\hline 100 miles $\times$ age $^{2}$ & -0.00053 & 0.00053 & 0.316 \\
\hline \multicolumn{4}{|l|}{ Interaction sex $\times$ age } \\
\hline Female $\times$ age & -0.0022 & 0.0054 & 0.688 \\
\hline \multicolumn{4}{|l|}{ Interaction se $\times$ age $^{2}$} \\
\hline Female $\times$ age $^{2}$ & 0.00069 & 0.00055 & 0.213 \\
\hline
\end{tabular}

Abbreviations: $\mathrm{C}$, coefficient; $\mathrm{SE}$, standard error.

\section{Correlation between performance differences between sexes and running speed}

Figure 7 presents the correlations between sex difference in running performance and running speed in men. The performance differences between sexes for the top and the top ten women and men ever were compared with running speed of men to find a potential relationship between sex difference and running speed. For both the fastest finishers ever $\left(r^{2}=0.0039, P=0.91\right)$ and the ten fastest finishers ever $\left(r^{2}=0.15, P=0.74\right)$, we found no correlation between sex difference and running speed.

A
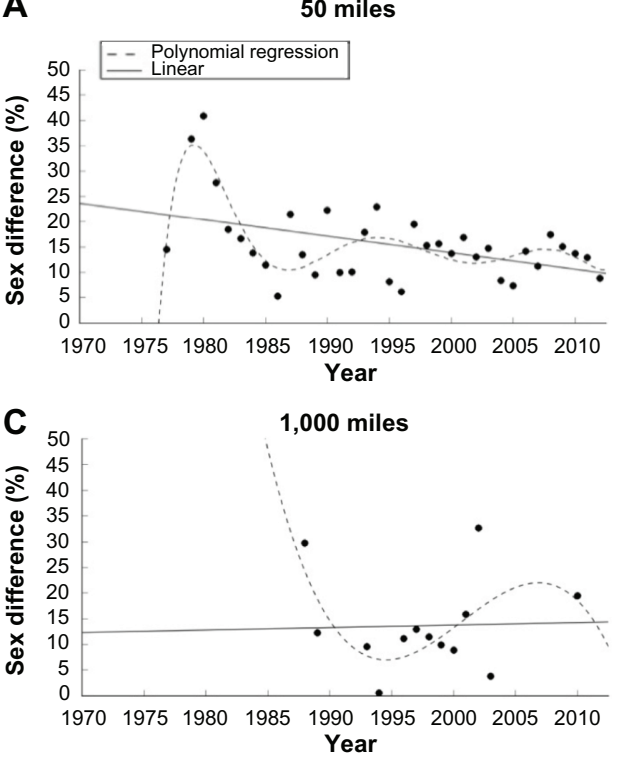

\section{Discussion}

This study intended to investigate the change in performance differences between sexes in running speed for the annual fastest ultramarathoners competing in events ranging from 50 miles to 3,100 miles and to determine the performance differences between sexes in running speed for the fastest finishers ever. The most important findings were 1) an exponential increase in events and finishers, 2) an improvement in running speed for the fastest women but not for all men groups, 3) a decrease in performance difference between sexes for the annual fastest in 50-mile events, an unchanged performance difference between sexes for the annual fastest in 100-mile events, and an increase in performance difference between sexes for the annual fastest in 3,100-mile events, 4) the annual ten fastest women reduced the performance difference between sexes in 50-mile and 100-mile events, and 5) the performance difference between sexes for the fastest and ten fastest women and men was at $\sim 17 \%$ for all race distances.

\section{Men-to-women ratio of finishers was lowest in the longest race distances}

The low number of female finishers is well-known in ultramarathons. ${ }^{14-16,19,20}$ The men-to-women ratio of finishers was highest in 50-mile and 100-mile and lowest in 1,000-mile and 3,100-mile. Therefore, women still represent a minority in ultraendurance running events. Similar findings were reported in recent studies. ${ }^{19,20}$ For example, in the $161 \mathrm{~km}$ Western States 100 Endurance Run, the number of finishers increased more in women than in men to $\sim 20 \%$ of the
B
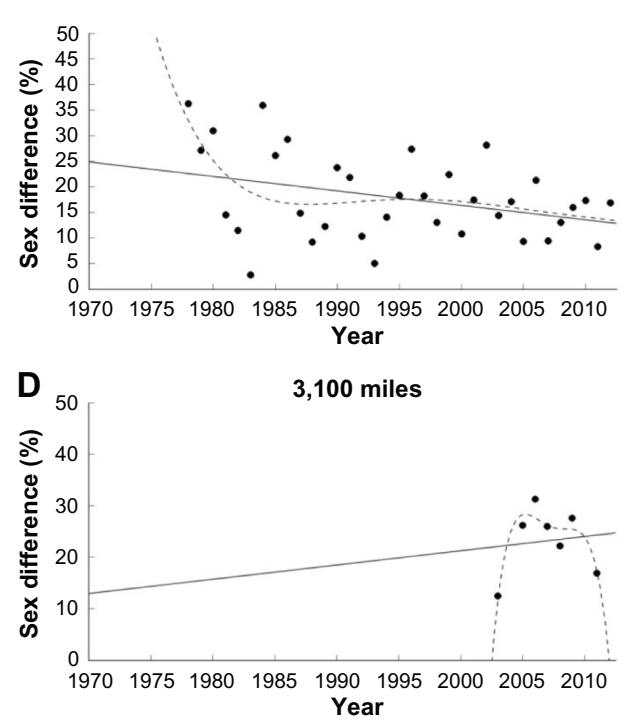

Figure 3 Sex differences across calendar years from 50-mile (A), 100-mile (B), I,000-mile (C), and 3,100-mile (D) events for the annual fastest runners. 
Table 7 Coefficients and standard errors from multivariate regression models for sex differences of the annual fastest runners for each calendar year

\begin{tabular}{|c|c|c|c|}
\hline & C & SE & $P$-value \\
\hline Intercept & 669.81 & 179.87 & $<0.001$ \\
\hline Year & -0.32 & 0.90 & 0.001 \\
\hline \multicolumn{4}{|l|}{ Distance } \\
\hline 3,100 miles & -45.55 & 20.33 & 0.001 \\
\hline 1,000 miles & -4.57 & 3.22 & 0.159 \\
\hline 100 miles & $\mathrm{I} .43$ & 1.92 & 0.458 \\
\hline \multicolumn{4}{|l|}{ Age } \\
\hline Linear & 0.12 & 0.35 & 0.973 \\
\hline Squared & -0.15 & 0.64 & 0.811 \\
\hline \multicolumn{4}{|c|}{ Interaction distance $\times$ age linear } \\
\hline 3,100 miles $\times$ age & 12.00 & 4.70 & 0.018 \\
\hline I,, 000 miles $\times$ age & -0.56 & 0.54 & 0.299 \\
\hline 100 miles $\times$ age & 0.20 & 0.45 & 0.653 \\
\hline \multicolumn{4}{|c|}{ Interaction distance $\times$ age $^{2}$} \\
\hline 3,100 miles $\times$ age $^{2}$ & -0.57 & 0.26 & 0.045 \\
\hline 1,000 miles $\times$ age $^{2}$ & 0.08 & 0.72 & 0.222 \\
\hline 100 miles $\times$ age $^{2}$ & 0.01 & 0.75 & 0.792 \\
\hline
\end{tabular}

Abbreviations: C, coefficient; SE, standard error.

total finishers in 2008. ${ }^{19}$ Similar findings have also been reported for other countries. Knechtle et $\mathrm{al}^{24}$ reported an average of $\sim 13 \%$ female finishers in the $100 \mathrm{~km}$ Lauf Biel held in Switzerland. For longer running distances, Knoth et a ${ }^{15}$ reported only $12.9 \%$ female finishers for a multistage Marathon des Sables ultramarathon held in Morocco. ${ }^{15}$ These numbers fit to our results, with a men-to-women ratio of $\sim 5: 1$.

In both 50-mile and 100-mile events, the annual ten fastest women could reduce the performance difference between sexes in running speed across years. Besides those trends, the men-to-women ratio decreased for both distances across years. Therefore, it seemed that the density of elite female runners increased because more women participated. Hunter and Stevens ${ }^{13}$ investigated the performance difference between sexes in the New York City Marathon in athletes competing between 1980 and 2010. They reported that lower participation rates and less depth among female competitors could amplify the sex difference in running speed. ${ }^{13}$ This raises the question of what would happen if an equal number of men and women would compete in ultraendurance sports. Men seemed to be in the majority in ultraendurance events, ${ }^{14-16,19,20}$ so the question remains hypothetical. We might never know the full part of the sex difference in performance due to the disproportion of female finishers. This might impact the behavior of choosing a running distance as more (mostly older) elite men might avoid the higher performance density of male marathon running ${ }^{25}$ and instead move to ultramarathons.

\section{Women reduced the performance difference between sexes linearly in 50-mile and 100-mile events}

It has been postulated that the performance difference between sexes in sports follows a nonlinear trend. ${ }^{23}$ Reinboud $^{23}$ addressed this topic and found that linear models were not suitable to explain changes in sex differences in running over time. However, in the present findings, the sex difference in running speed decreased linearly in the last $\sim 40$ years in the annual fastest runners in 50-mile races and in the annual ten fastest runners in 50-mile and 100-mile events. Due to the lower number of female finishers in longer distances, for 1,000-mile and 3,100-mile events we could perform only the regression for the annual fastest. In this regression, no change in performance difference between sexes occurred. Based on these findings, women reduced the performance difference between sexes in 50-mile and 100-mile events and due to the linear decrease they may continue reducing this gap.

A possible explanation for this finding might be the investigated time span of $\sim 40$ years from 1972-2012, which might be too short for a firm data analysis. Whipp and Ward ${ }^{1}$ reported similar findings in 1992 for marathon runners.

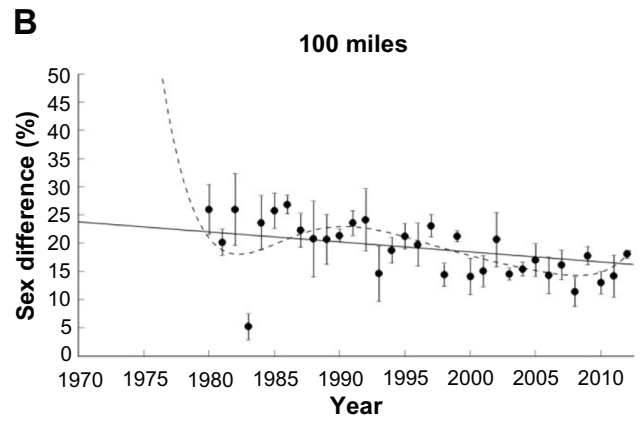

Figure 4 Sex differences across calendar years in 50-mile and 100-mile events for the annual ten fastest runners. 
Table 8 Coefficients and standard errors from multivariate regression models for sex differences of the annual ten fastest runners for each calendar year

\begin{tabular}{llll}
\hline & C & SE & P-value \\
\hline Intercept & 638.63 & 48.7 I & $<0.000$ I \\
Year & -0.3 I & 0.024 & $<0.000$ I \\
$\begin{array}{l}\text { Distance } \\
\quad \text { I00 miles }\end{array}$ & 0.960 & 0.500 & 0.0056 \\
$\begin{array}{l}\text { Age } \\
\quad \text { Linear }\end{array}$ & -0.0190 & 0.0620 & 0.750 \\
$\quad$ Squared & -0.0042 & 0.0092 & 0.642 \\
$\begin{array}{l}\text { Interaction distance } \times \text { age linear } \\
\quad \text { I00 miles } \times \text { age }\end{array}$ & 0.0027 & 0.083 & 0.974 \\
$\begin{array}{l}\text { Interaction distance } \times \text { age }^{2} \\
\quad \text { I00 miles } \times \text { age }^{2}\end{array}$ & 0.0092 & 0.011 & 0.427 \\
\hline
\end{tabular}

Abbreviations: C, coefficient; SE, standard error.

Today, we know that the performance difference between sexes in marathon running is a polynomial change rather than a linear change. ${ }^{23}$ We assume to see a similar development in ultramarathon running in the next years. In distances of 200 miles and longer, women might not reduce the performance difference between sexes. The reason for this finding remains unclear. A possible explanation might be the low number of overall finishers in 200-mile, 1,000-mile, and 3,100-mile events.

\section{Running performance differences between sexes with no change with increasing distance}

Although a few women were able to beat men in ultramarathon races, ${ }^{6-8}$ we found a performance difference between sexes of $\sim 17 \%$ for all race distances. This performance difference between sexes was higher compared to the $\sim 11 \%-12 \%$ reported by Thibault et al ${ }^{10}$ and Coast et al. ${ }^{11}$ Starting from $~ 15 \%$ in 50-mile events, the performance difference between sexes in running speed increased up to $22 \%$ in 3,100-mile races for the annual fastest runners. Indeed, the performance difference between sexes in running speed showed no change between 50-mile and 3,100-mile events for the fastest runners ever. Therefore, the hypothesis that women will outrun men in longer ultramarathons cannot be confirmed. ${ }^{3}$

Concerning running, the triathlon is an interesting comparable sport, as running is part of it. In triathlon, the changes in sex difference in performance across the years differ among the various ultradistances. ${ }^{26,27}$ While the performance difference between sexes in the Ironman World Championship "Ironman Hawaii" decreased for overall race times, ${ }^{28,29}$ it increased in Triple Iron ultratriathlons and in Deca Iron ultratriathlons. ${ }^{26}$ Of interest are the split times in the ultratriathlon, as they
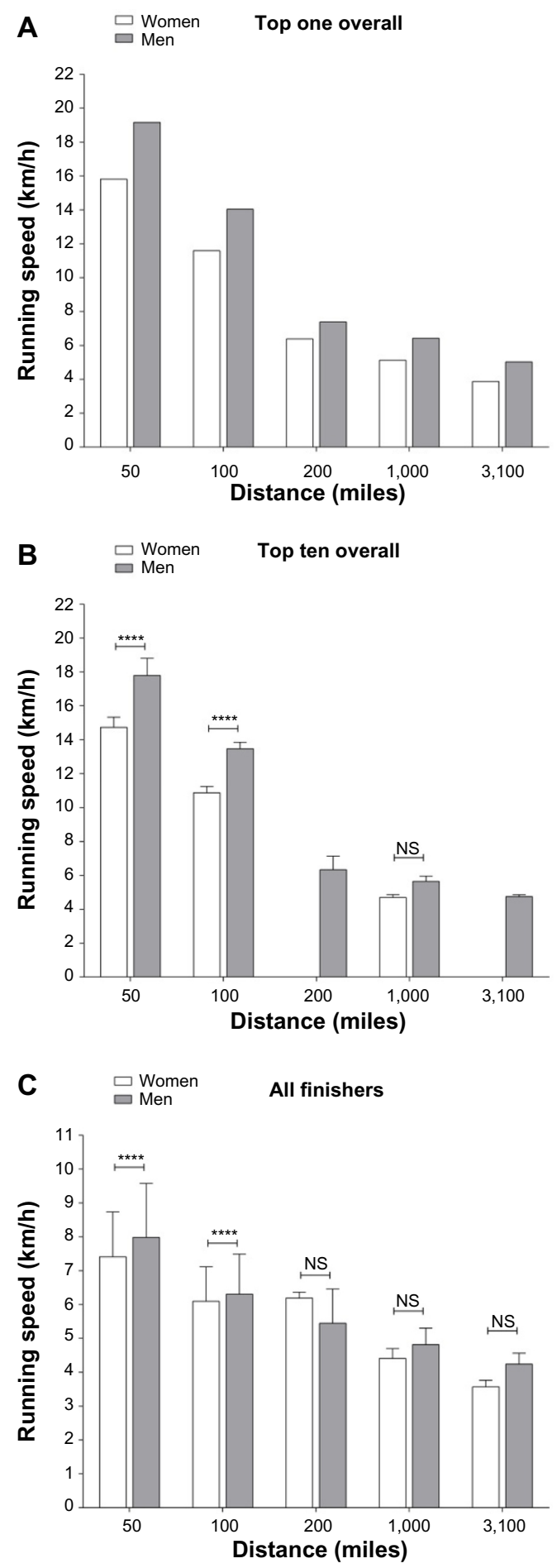

Figure 5 Running speeds from 50-mile to 3,100-mile events. Notes: (A) Fastest runner ever. (B) Ten fastest runners ever. (C) All finishers. $* * * * P<0.0001$.

Abbreviation: NS, nonsignificant.

can be directly compared to ultrarunning. Rüst et $\mathrm{al}^{30}$ found a decrease in the performance difference between sexes in running split times in Ironman triathlons but not in Double, Triple, or Deca Iron ultratriathlons. Women therefore reduced the performance difference between sexes only in Ironman 
A

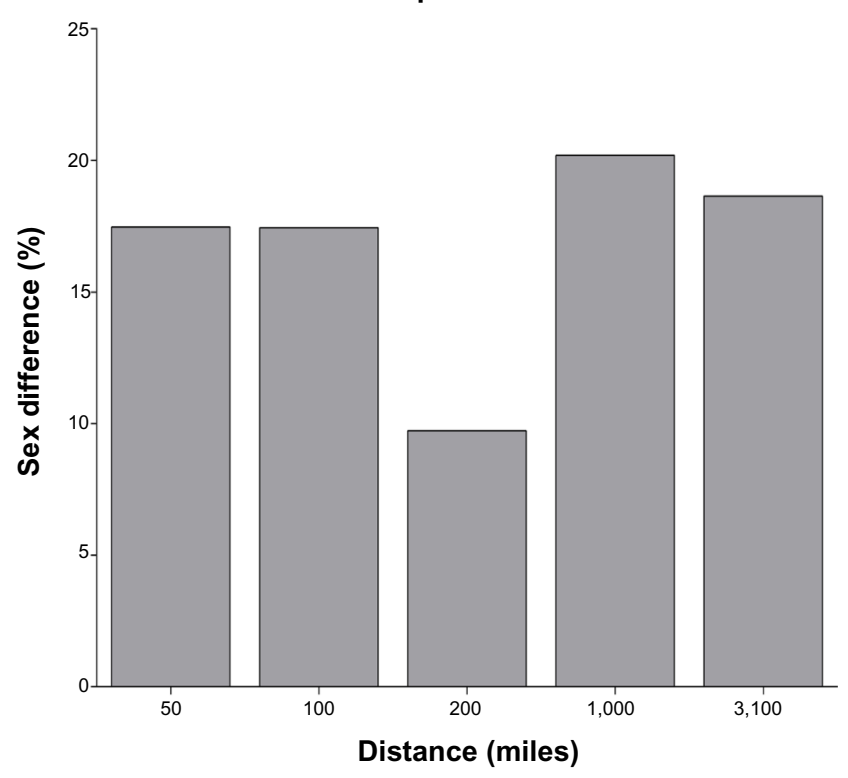

B

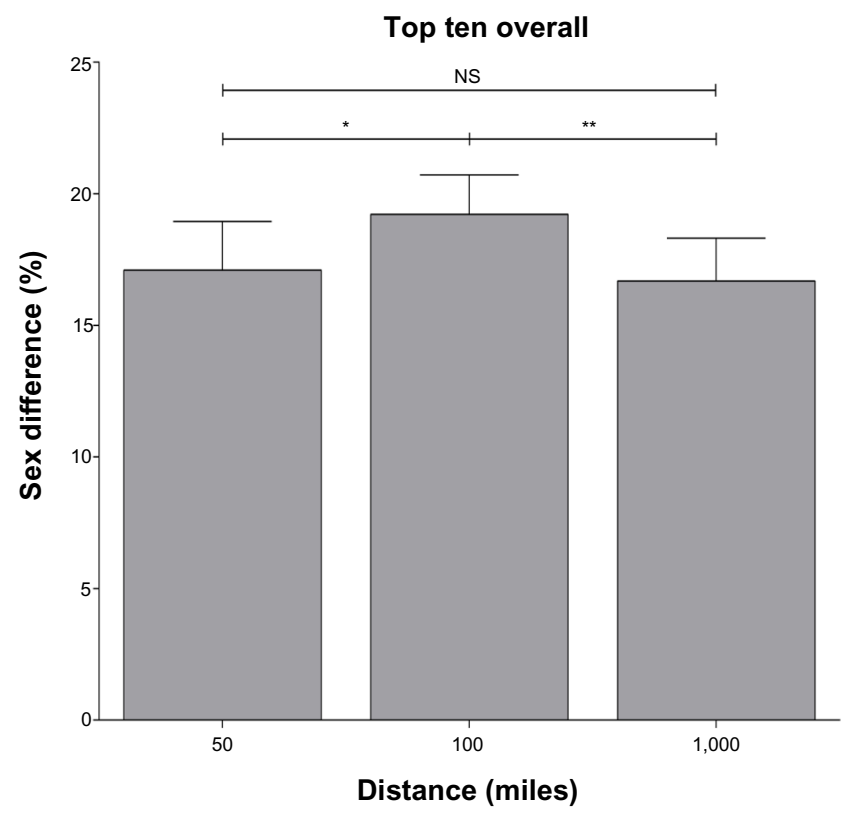

Figure 6 Sex difference in running speed from 50-mile to 3,100-mile events. Notes: (A) Fastest runner ever. (B) Ten fastest runners ever. $* P<0.05 ; * * P<0.01$. Abbreviation: NS, nonsignificant.

triathlons, where their participation rate was the highest among ultratriathlons. ${ }^{30}$ Furthermore, the sex difference in performance increased with increasing length of an event, from $\sim 11.3 \%$ in the Ironman World Championship Hawaii "Ironman Hawaii" ${ }^{29}$ to $\sim 30 \%$ in Deca Iron ultratriathlons. ${ }^{26}$

The performance difference between sexes in running speed showed no change between 50-mile and 3,100-mile events when the ten fastest finishers for each distance were considered. In other sports such as swimming, a decrease in sex difference of performance was reported with increasing race distance. ${ }^{31,32}$ Wild et al ${ }^{32}$ found that female finalists and champions at the Olympic Games and FINA World Championships reduced the performance difference between sexes with increasing race distance. However, in single events, the sex difference in performance was unchanged. For example, in the $26.4 \mathrm{~km}$ open-water ultraswim Marathon Swim in Lake Zurich, Switzerland, the sex difference in open-water ultraswimming performance of $\sim 11.5 \%$ remained unchanged between 1987 and 2011. ${ }^{31}$ The investigation of longer swimming distances may show that women might be able to outperform men in swimming with increasing race distance. This may raise the question whether the performance difference between sexes in ultrarunning would decrease as well with increasing distance. As a result of the low finisher numbers in 200-mile, 1,000mile and 3,100-mile events, a statistic analysis of the fastest ten finishers ever could not be performed. Therefore, further studies may be required, including other distances longer than 100 miles, such as $200 \mathrm{~km}$ or 1,000 km events.

\section{Increase in sex difference in running speed for the annual fastest in 3,100-mile}

A further important finding was a decrease in performance differences between sexes for the annual fastest in 50-mile events, an unchanged performance difference between sexes for the annual fastest in 100-mile events, and an increase in performance difference between sexes for the annual fastest in 3,100-mile events. Basically, the best women were able to close the sex gap in the shortest ultramarathon distance (ie, 50 miles) but the sex difference widened in the longest ultramarathon distance (ie, 3,100 miles). These differences might be explained by differences in anthropometry and physiology between women and men. However, a more likely reason might be the lack of experience in women competing in the very long ultramarathon distances. Women have not been competing in the ultralong distances for very long. ${ }^{11}$ This lack of experience might be the reason for the sex difference in performance apart from any physical or physiological differences. ${ }^{11}$ This is also reflected in the differences in the men-to-women ratio of finishers from 50-mile to 3,100-mile events and in the lower number of female finishers in the very long ultramarathons.

\section{Anthropometric and physiological considerations}

A possible explanation for why the fastest women can compete with the fastest men in swimming but not in running might be explained by anthropometric and physiological 

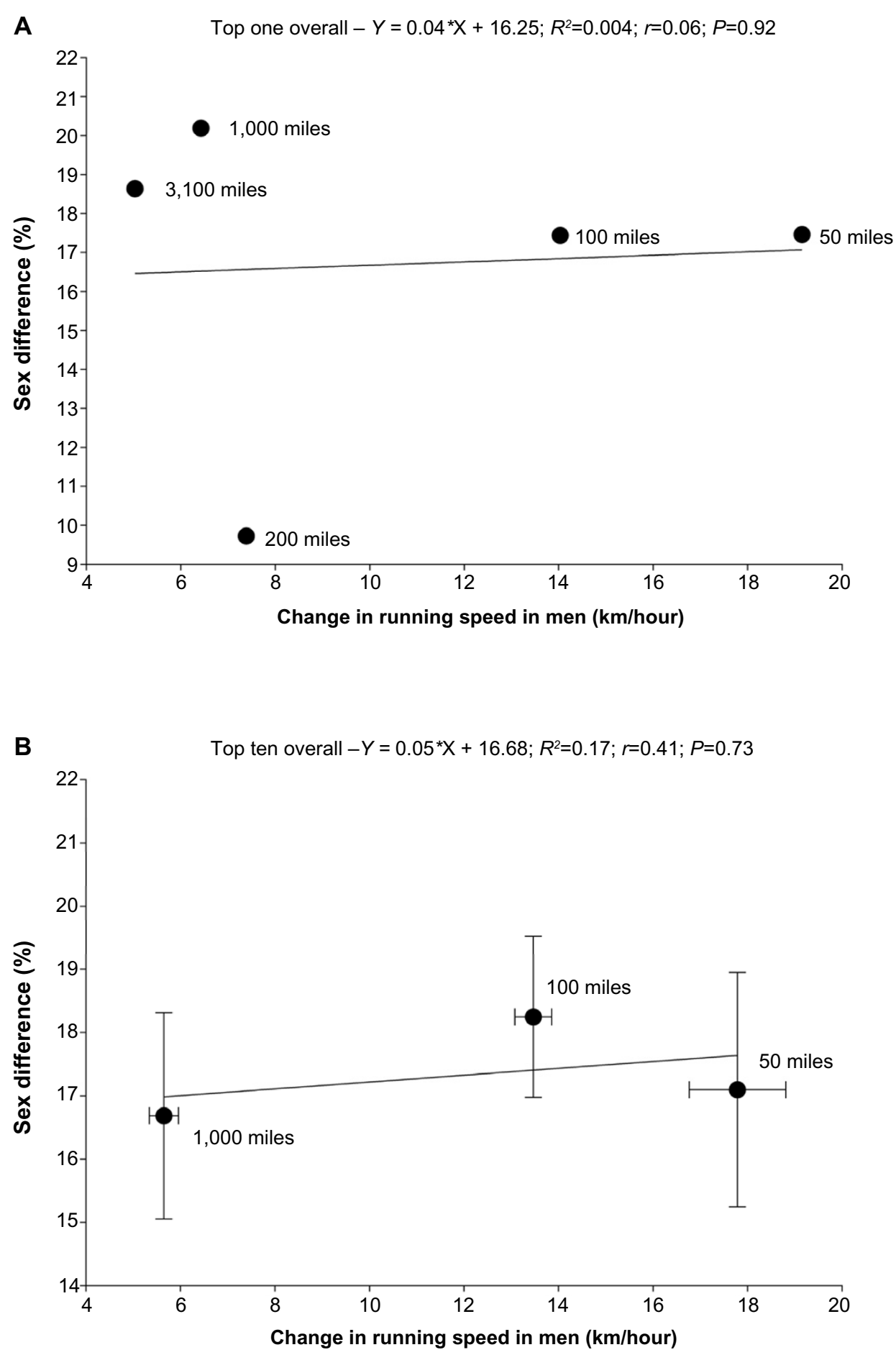

Figure 7 Sex differences in relation to running speed from 50-mile to 3,100-mile events. Notes: (A) Fastest runners ever. (B) Ten fastest runners ever.

differences between women and men. ${ }^{33-43} \mathrm{~A}$ higher body-fat percentage could be an advantage while swimming in cold water, ${ }^{34}$ whereas it may be a disadvantage to carry the excess weight over long distances in running. ${ }^{35}$ Another important difference in anthropometry between sexes is bone density, which seemed to have an important influence in buoyancy for swimmers but may favor stronger bone structure and therefore fewer injuries. ${ }^{33}$ Men have a higher skeletal muscle mass than women, ${ }^{36,37}$ which could impact performance as muscle mass is lost in ultraendurance running. ${ }^{38}$

Physiological characteristics such as maximum oxygen uptake $^{39-41}$ might explain the sex difference in peak running 
speed. ${ }^{13}$ Men have larger hearts and therefore both a higher stroke volume and a higher cardiac output. ${ }^{42}$ The vascularization of the skeletal muscle mass is lower in women due to their lower blood volume. ${ }^{36}$ This finding results in a $\sim 15 \%-25 \%$ lower maximum oxygen uptake in female than in male athletes. ${ }^{36,43}$ Therefore, different anthropometric parameters seem to impact performance differently in distinct sports. The comparison of sex difference in performance in different sports may therefore be impossible. Furthermore, these physiological differences might be influenced by training characteristics. $^{44}$

Other differences between women and men to explain sex differences in performance are differences in muscle fiber type, muscle fiber length, pennation angle, and fascicle length. ${ }^{4}$ The differences in muscle fiber characteristics are due to the higher concentrations of circulating testosterone in men. ${ }^{4}$ Also, body mass, hemoglobin content, and substrate utilization play significant roles in weight-bearing ultraendurance events.

\section{Strengths, weaknesses, limitations, and implications for future research}

The strength of the study is that the statistical analysis included both linear and nonlinear regression analyses, as the change in performance difference between sexes in endurance is assumed to be nonlinear. ${ }^{23}$ Furthermore, the data set is the most extensive for ultramarathons in miles so far. A weakness could be that some events from 50 miles to 3,100 miles were not recorded in the records of the Deutsche Ultramarathon Vereinigung and therefore their results were lost for the data set. $^{22}$ The increase in the number of both male and female runners in ultramarathons across years could bias the results itself. The performance density in male runners might be higher than in female runners since more men than women are running these distances. More gifted male runners may be attracted to this sport and they may train harder than women so that these environmental factors may be misinterpreted as a genetic difference. Training characteristics might influence running performance and explain some part of the sex difference found here. ${ }^{44}$ Deaner ${ }^{45}$ studied distance running to show a sex difference in competitiveness. He concluded that at least some part of what was considered a given genetic difference in performance can be attributed to men's greater training motivation.

One of the major confounders is the limitation of retrospectively evaluating times and not being able to observe other measures that may influence outcome, ie, physiological and psychological factors. The study is limited because variables such as physiological parameters ${ }^{36}$ anthropometric characteristics, ${ }^{46}$ training data, ${ }^{47}$ previous experience, ${ }^{48}$ nutrition, ${ }^{49,50}$ fluid intake, ${ }^{51}$ and environmental conditions ${ }^{52}$ were not considered. These variables may have had an influence on race outcome. There will be a relative inability to evaluate the decrease in performance differences between sexes in longer ultramarathon distances due to the limited data of female ultramarathoners competing in the very long ultramarathons. Future studies need to investigate running events held in kilometers and time-limited races held in hours and days to increase the sample size of women in ultramarathons. Future studies should also investigate the motivation of female ultramarathoners compared to male ultramarathoners. Most probably, women have become more motivated to compete faster and to beat men in ultramarathons.

\section{Conclusion}

In ultramarathons from 50 miles to 3,100 miles held between 1971 and 2012, the number of events and finishers increased exponentially, the men-to-women ratio decreased across years and was highest in 50-mile events and lowest in 3,100-mile events, the sex difference in running speed for the annual fastest in 50-mile events decreased, remained unchanged for the annual fastest in 100-mile events, but increased for the annual fastest in 3,100-mile events, the annual ten fastest women reduced the performance difference between sexes in 50-mile and 100-mile events and the performance difference between sexes for the fastest and ten fastest women and men was at $\sim 17 \%$ for all race distances. Although women reduced the sex difference in running speed in the shorter ultramarathon distances (ie, 50 miles and 100 miles) they seemed unable to close the sex gap in the very long ultramarathon distances (ie, 3,100 miles). The linear decrease in sex difference for 50-mile and 100-mile events suggests that women may continue reducing the gap relative to men in 50-mile and 100-mile events but not in the longer ultramarathon distances. Further studies of other ultramarathons of different distances need to investigate if women keep closing the sex gap in the future.

\section{Disclosure}

The authors report no conflicts of interest in this work.

\section{References}

1. Whipp BJ, Ward SA. Will women soon outrun men? Nature. 1992; 355(6355):25

2. Bam J, Noakes TD, Juritz J, Dennis SC. Could women outrun men in ultramarathon races? Med Sci Sports Exerc. 1997;29(2):244-247.

3. Beneke R, Leithäuser RM, Doppelmayr M. Women will do it in the long run. Br J Sports Med. 2005;39(7):410. 
4. Cheuvront SN, Carter R, Deruisseau KC, Moffatt RJ. Running performance differences between men and women:an update. Sports Med. 2005;35(12):1017-1024.

5. Tatem AJ, Guerra CA, Atkinson PM, Hay SI. Athletics: momentous sprint at the 2156 Olympics? Nature. 2004;431(7008):525.

6. LaRusso R. The Sri Chinmoy USA/TAC 24-Hour National Championship, 1989 [webpage on the Internet]. New York, NY: Sri Chinmoy Marathon Team; 2011. Available from: http://us.srichinmoyraces.org/ archives/1989/24-hour. Accessed December 8, 2014.

7. Badwater. Badwater 135 race results, 2000 to the present [webpage on the Internet]. Death Valley, CA: Badwater; 2014. Available from: http://www.badwater.com/results. Accessed December 8, 2014.

8. Abichal. Multiday.com Ultrarunning News: Deutschlandlauf 2007 [webpage on the Internet]. Multidays.com; 2007. Available from: http:// multidays.com/deutschlandlauf-2007. Accessed December 8, 2014.

9. Swimming World Magazine. 2012 London Olympics: China's Ye Shiwen crushes world record in 400 IM [webpage on the Internet]. Sedona, AZ: Sports Publications, Inc. 2012. Available at: http://www. swimmingworldmagazine.com/lane9/news/World/31415.asp. Accessed December 8, 2014.

10. Thibault V, Guillaume M, Berthelot G, et al. Women and men in sport performance: the gender gap has not evolved since 1983. J Sports Sci Med. 2010;9(2):214-223.

11. Coast JR, Blevins JS, Wilson BA. Do gender differences in running performance disappear with distance? Can J Appl Physiol. 2004;29(2):139-145.

12. Hunter SK, Stevens AA, Magennis K, Skelton KW, Fauth M. Is there a sex difference in the age of elite marathon runners? Med Sci Sports Exerc. 2011;43(4):656-664.

13. Hunter SK, Stevens AA. Sex differences in marathon running with advanced age: physiology or participation? Med Sci Sports Exerc. 2013;45(1):148-156.

14. Zingg M, Rüst CA, Lepers R, Rosemann T, Knechtle B. Master runners dominate 24-h ultramarathons worldwide-a retrospective data analysis from 1998 to 2011. Extrem Physiol Med. 2013;2(1):21.

15. Knoth C, Knechtle B, Rüst CA, Rosemann T, Lepers R. Participation and performance trends in multistage ultramarathons-the 'Marathon des Sables' 2003-2012. Extrem Physiol Med. 2012;1(1):13.

16. Eichenberger E, Knechtle B, Rüst CA, Rosemann T, Lepers R. Age and sex interactions in mountain ultramarathon running - the Swiss Alpine Marathon. Open Access J Sports Med. 2012;3:73-80.

17. Speechly DP, Taylor SR, Rogers GG. Differences in ultra-endurance exercise in performance-matched male and female runners. Med Sci Sports Exerc. 1996;28(3):359-365.

18. Hoffman MD. Ultramarathon trail running comparison of performance-matched men and women. Med Sci Sports Exerc. 2008; 40(9):1681-1686.

19. Hoffman MD, Ong JC, Wang G. Historical analysis of participation in $161 \mathrm{~km}$ ultramarathons in North America. Int J Hist Sport. 2010;27(11): 1877-1891.

20. Hoffman MD, Fogard K. Demographic characteristics of 161-km ultramarathon runners. Res Sports Med. 2012;20(1):59-69.

21. Deaner RO, Mitchell D. More men run relatively fast in US road races, 1981-2006: a stable sex difference in non-elite runners. Evol Psychol. 2011;9(4):600-621.

22. Deutsche Ultramarathon Vereinigung eV [homepage on the Internet]. Hambrücken, Germany: Deutsche Ultramarathon Vereinigung eV; 2014. Available from: http://www.ultra-marathon.org. Accessed December 8, 2014. German.

23. Reinboud W. Linear models can't keep up with sport gender gap. Nature. 2004;432(7014):147; author reply 147.

24. Knechtle B, Rüst CA, Rosemann T, Lepers R. Age-related changes in 100-km ultra-marathon running performance. Age (Dordr). 2012;34(4): 1033-1045

25. Rüst CA, Knechtle B, Rosemann T, Lepers R. Analysis of performance and age of the fastest 100-mile ultra-marathoners worldwide. Clinics (Sao Paulo). 2013;68(5):605-611.
26. Knechtle B, Knechtle P, Lepers R. Participation and performance trends in ultra-triathlons from 1985 to 2009. Scand J Med Sci Sports. 2011;21(6):e82-e90.

27. Rüst CA, Knechtle B, Knechtle P, Rosemann T, Lepers R. Participation and performance trends in Triple Iron ultra-triathlon - a cross-sectional and longitudinal data analysis. Asian J Sports Med. 2012;3(3):145-152.

28. Lepers R. Analysis of Hawaii ironman performances in elite triathletes from 1981 to 2007. Med Sci Sports Exerc. 2008;40(10): $1828-1834$

29. Rüst CA, Knechtle B, Rosemann T, Lepers R. Sex difference in race performance and age of peak performance in the Ironman Triathlon World Championship from 1983 to 2012. Extrem Physiol Med. 2012;1(1): 15 .

30. Rüst CA, Rosemann T, Knechtle B. Performance and sex difference in ultra-triathlon performance from Ironman to Double Deca Iron ultratriathlon between 1978 and 2013. Springerplus. 2014;3:219.

31. Eichenberger E, Knechtle B, Knechtle P, et al. Sex difference in openwater ultra-swim performance in the longest freshwater lake swim in Europe. J Strength Cond Res. 2013;27(5):1362-1369.

32. Wild S, Rüst CA, Rosemann T, Knechtle B. Changes in sex difference in swimming speed in finalists at FINA World Championships and the Olympic Games from 1992 to 2013. BMC Sports Sci Med Rehabil. 2014;6:25.

33. Gregson CL, Steel SA, O'Rourke KP, et al. 'Sink or swim': an evaluation of the clinical characteristics of individuals with high bone mass. Osteoporos Int. 2012;23(2):643-654.

34. Weitkunat T, Knechtle B, Knechtle P, Rüst CA, Rosemann T. Body composition and hydration status changes in male and female open-water swimmers during an ultra-endurance event. J Sports Sci. 2012;30(10):1003-1013.

35. Knechtle B, Duff B, Schulze I, Kohler G. The effects of running 1,200 $\mathrm{km}$ within 17 days on body composition in a female ultrarunnerDeutschlandlauf 2007. Res Sports Med. 2008;16(3):167-188.

36. Lynch SL, Hoch AZ. The female runner: gender specifics. Clin Sports Med. 2010;29(3):477-498.

37. Lindle RS, Metter EJ, Lynch NA, et al. Age and gender comparisons of muscle strength in 654 women and men aged 20-93 yr. J Appl Physiol (1985). 1997;83(5):1581-1587.

38. Schütz UH, Billich C, König K, et al. Characteristics, changes and influence of body composition during a $4486 \mathrm{~km}$ transcontinental ultramarathon: results from the TransEurope FootRace mobile whole body MRI-project. BMC Med. 2013;11:122.

39. Billat VL, Demarle A, Slawinski J, Paiva M, Koralsztein JP. Physical and training characteristics of top-class marathon runners. Med Sci Sports Exerc. 2001;33(12):2089-2097.

40. Joyner MJ. Physiological limiting factors and distance running: influence of gender and age on record performances. Exerc Sport Sci Rev. 1993;21:103-133.

41. Sparling PB. A meta-analysis of studies comparing maximal oxygen uptake in men and women. Res Q Exerc Sport. 1980;51(3): $542-552$.

42. Pavlik G, Olexó Z, Bánhegyi A, Sidó Z, Frenkl R. Gender differences in the echocardiographic characteristics of the athletic heart. Acta Physiol Hung. 1999;86(3-4):273-278.

43. Cureton K, Bishop P, Hutchinson P, Newland H, Vickery S, Zwiren L. Sex difference in maximal oxygen uptake. Effect of equating haemoglobin concentration. Eur J Appl Physiol Occup Physiol. 1986;54(6): 656-660.

44. Tanda G, Knechtle B. Marathon performance in relation to body fat percentage and training indices in recreational male runners. Open Access J Sports Med. 2013;4:141-149.

45. Deaner RO. Distance running as an ideal domain for showing a sex difference in competitiveness. Arch Sex Behav. 2013;42(3):413-428.

46. Knechtle B, Rüst CA, Knechtle P, Rosemann T. Does muscle mass affect running times in male long-distance master runners? Asian $J$ Sports Med. 2012;3(4):247-256. 
47. Hagan RD, Smith MG, Gettman LR. Marathon performance in relation to maximal aerobic power and training indices. Med Sci Sports Exerc. 1981;13(3):185-189.

48. Knechtle B, Knechtle P, Rosemann T, Senn O. What is associated with race performance in male 100-km ultra-marathoners - anthropometry, training or marathon best time? J Sports Sci. 2011;29(6):571-577.

49. Maughan RJ, Shirreffs SM. Nutrition for sports performance: issues and opportunities. Proc Nutr Soc. 2012;71(1):112-119.

50. Rodriguez NR, Di Marco NM, Langley S; American Dietetic Association; Dietitians of Canada; American College of Sports Medicine. American College of Sports Medicine position stand. Nutrition and athletic performance. Med Sci Sports Exerc. 2009;41(3):709-731.
51. Williams J, Tzortziou Brown V, Malliaras P, Perry M, Kipps C. Hydration strategies of runners in the London Marathon. Clin J Sport Med. 2012;22(2):152-156.

52. Ely MR, Cheuvront SN, Roberts WO, Montain SJ. Impact of weather on marathon-running performance. Med Sci Sports Exerc. 2007;39(3):487-493.

\section{Publish your work in this journal}

Open Access Journal of Sports Medicine is an international, peer-reviewed, open access journal publishing original research, reports, reviews and commentaries on all areas of sports medicine. The manuscript management system is completely online and includes a very quick and fair peer-review system.
Visit http://www.dovepress.com/testimonials.php to read real quotes from published authors. 